\title{
Transient changes in the endocannabinoid system after acute and chronic ethanol exposure and abstinence in the rat: a combined PET and microdialysis study
}

\author{
Jenny Ceccarini • Cindy Casteels • Michel Koole • \\ Guy Bormans $\cdot$ Koen Van Laere
}

Received: 23 January 2013 / Accepted: 3 May 2013

(C) Springer-Verlag Berlin Heidelberg 2013

\begin{abstract}
Purpose Recent biochemical and post-mortem evidence suggests involvement of the endocannabinoid system in alcohol drinking behaviour and dependence. Using $\left[{ }^{18}\right.$ F]MK-9470 small-animal PET imaging, our primary objective was to evaluate in vivo type 1 cannabinoid receptor (CB1R) binding changes in rats subjected to several ethanol conditions: (1) at baseline, (2) after acute intraperitoneal administration of ethanol $(4 \mathrm{~g} / \mathrm{kg})$ or saline, (3) after 7 days of forced chronic ethanol consumption, and (4) after
\end{abstract}

J.C. and C.C. contributed equally to this work.

J. Ceccarini $\cdot$ C. Casteels $\cdot$ M. Koole $\cdot$ K. Van Laere

Division of Nuclear Medicine, University Hospitals Leuven,

KU Leuven, 3000 Leuven, Belgium

J. Ceccarini $\cdot$ C. Casteels $\cdot$ M. Koole $\cdot$ K. Van Laere

Department of Imaging and Pathology,

KU Leuven, 3000 Leuven, Belgium

J. Ceccarini $\cdot$ C. Casteels $\cdot$ M. Koole $\cdot$ G. Bormans $\cdot$ K. Van Laere

MoSAIC, Molecular Small Animal Imaging Center,

KU Leuven, 3000 Leuven, Belgium

G. Bormans

Department of Pharmaceutical and Pharmacological Sciences,

Laboratory for Radiopharmacy,

KU Leuven, 3000 Leuven, Belgium

K. Van Laere

LIND, Leuven Institute for Neurobiology and Disease,

KU Leuven, 3000 Leuven, Belgium

J. Ceccarini $(\bowtie)$

Division of Nuclear Medicine,

University Hospital Leuven - Gasthuisberg,

Herestraat 49, 3000 Leuven, Belgium

e-mail: jenny.ceccarini@uzleuven.be abstinence for 7 and 14 days. Secondly, levels of anandamide (AEA) in the nucleus accumbens (NAcc) were investigated in the same animals using in vivo microdialysis and correlated with the changes in CB1R binding.

Methods In total, 28 male Wistar rats were investigated. Small-animal PET was done on a FOCUS-220 tomograph with $\left[{ }^{18} \mathrm{~F}\right] \mathrm{MK}-9470$. Parametric images of $\left[{ }^{18} \mathrm{~F}\right] \mathrm{MK}-9470$ binding based on standard uptake values (SUV, as a measure of CB1R binding) were generated. Images were normalized to Paxinos space and analysed voxel-wise using SPM8 $\left(p_{\text {height }}=0.005 ; k_{\text {ext }}=200\right)$. The AEA content was quantified using HPLC with tandem mass spectrometry detection.

Results Acute ethanol administration increased relative CB1R binding in the NAcc that was positively correlated with the change in AEA levels of that region. In contrast, compared to rats at baseline, AEA levels in the NAcc were not significantly different in rats after chronic ethanol consumption or after a 14-day abstinence period. Chronic ethanol consumption decreased relative CB1R binding in the hippocampus and caudate-putamen, whereas same regions showed increased relative CB1R binding after 7 and 14 days of abstinence compared to the baseline condition. After 7 and 14 days of abstinence, relative CB1R binding additionally decreased in the orbitofrontal cortex. The magnitude of the hippocampal and frontal changes was highly correlated with daily ethanol intake.

Conclusion This study provides in vivo evidence that acute ethanol consumption is associated with enhanced endocannabinoid signalling in the NAcc, indicated by an increased CB1R binding and AEA content. In addition, chronic ethanol exposure leads to regional dysfunctions in CB1R levels, involving the hippocampus and caudateputamen that are reversible within 2 weeks in this animal model. 
Keywords Type 1 cannabinoid receptor · Small-animal PET $\cdot\left[{ }^{18} \mathrm{~F}\right] \mathrm{MK}-9470 \cdot$ Microdialysis $\cdot$ Anandamide . Ethanol

\section{Introduction}

The isolation of the principle psychoactive ingredient of cannabis, $\Delta^{9}$-tetrahydrocannabinol led to the identification of the endocannabinoid system (ECS). The ECS is a neuromodulatory system that comprises a family of naturally occurring lipids, the endocannabinoids, of which anandamide (AEA) and 2-arachidonoylglycerol (2-AG) are the best characterized. It also comprises transport and degradation proteins and two types of cannabinoid receptors [1]. Type 1 cannabinoid receptor (CB1R) is abundantly expressed throughout the brain, especially in those brain areas involved in drug addiction, such as the striatum, hippocampus, cerebellum and cortex [2]. Acting through the activation of $\mathrm{Gi}$ proteins, CB1R stimulation is thought to modulate glutamatergic and GABAergic neurotransmitter release [1].

Recent biochemical and post-mortem evidence suggests involvement of the ECS in alcohol drinking behaviour and dependence (for review see Pava and Woodward [3]). Acute and short-term exposure to ethanol leads to decreased levels of AEA in reward-related and motor-related regions of the rat brain [4-6]. Also, decreases in CB1R gene expression and binding of the caudate-putamen, amygdala and prefrontal cortex in the rat brain have been observed after acute [7] and short-term exposure to alcohol [8]. The effects of chronic alcohol exposure are less consistent, with some studies showing increased endocannabinoid levels in reward-related brain areas [9-11], and others showing either a decrease [9, 12] or no change $[11,12]$. Also for CB1R expression, density and functionality, inconsistent results have been found in other studies, which have shown that CB1R is either downregulated and reduced in the hippocampus and caudate-putamen of rodents chronically exposed to ethanol $[10,13]$, or unchanged [14]. In alcoholic patients, a profound cortical and subcortical loss of CB1R availability in vivo is found that is irreversible after several weeks of imposed alcohol abstinence [15, 16], while acute ethanol administration in healthy volunteers results in a whole-brain increase in CB1R binding [17].

So far, there are only in vitro and ex vivo data on the involvement of the ECS in experimental ethanol drinking behaviour and dependence [3]. Studies of ECS changes under experimental alcoholic conditions have focused on the striatum, cortex and cerebellum, and have not assessed other brain regions. PET imaging allows the whole-brain evaluation of ECS components in vivo, while simultaneous microdialysis enables assessment of the relationship between endogenous neurotransmitter changes and observed receptor binding status. In vivo imaging of CB1Rs in the rat brain has recently become feasible following the development of selective radioligands, among which is $\left[{ }^{18} \mathrm{~F}\right] \mathrm{MK}$ $9470[18,19]$.

Our primary objective was to evaluate $\mathrm{CB} 1 \mathrm{R}$ binding changes in vivo in rats under conditions of forced ethanol administration in comparison to abstinence. Secondly, levels of brain AEA in the nucleus accumbens (NAcc) were investigated in the same animals using in vivo microdialysis and were correlated with the changes in regional CB1R binding.

\section{Materials and methods}

Animals

In total, 28 adult male Wistar rats (body weight at the start of the experiments $330 \pm 21 \mathrm{~g}$; Charles River Laboratories, L'Arbresle, France) were used and were housed in individual cages with food and liquid (either water or ethanol depending on the ethanol condition) freely accessible in a 12-h light/dark cycle under controlled conditions of temperature and humidity. All experiments were approved by the local Animal Ethics Committee and conducted according to European Ethics Committee guidelines (decree 86/609/EEC).

\section{Ethanol treatments}

The effects of acute exposure to ethanol on CB1R binding in vivo were evaluated in 12 rats using a previously described acute ethanol administration paradigm [4] (Fig. 1). Ethanol was dissolved in sterile $0.9 \%$ (weight/volume, w/v) saline $(\mathrm{NaCl})$ to obtain a $15 \%(\mathrm{w} / \mathrm{v})$ ethanol solution and administered intraperitoneally (IP) at a dose of $4 \mathrm{~g} / \mathrm{kg}$ of body mass to six rats $90 \mathrm{~min}$ prior to tracer injection. To avoid possible confounding effects of the IP administration on CB1R binding, a group of six control rats received a similar volume of a $0.9 \%$ saline solution IP (Fig. 1). The acute IP administration of $4 \mathrm{~g}$ of ethanol $/ \mathrm{kg}$ of body mass had previously been shown to decrease endocannabinoid (AEA and palmitoyl ethanolamide) levels in the NAcc, cerebellum and hippocampus at $90 \mathrm{~min}$ after ethanol administration [4].

Effects of chronic exposure to ethanol on CB1R binding in vivo was further evaluated in a second group of 12 rats, which were subjected to consecutive phases of alcoholization, i.e. forced chronic ethanol administration and ethanol abstinence, as previously described [12] (Fig. 1). For the chronic phase, rats were housed individually with a liquid diet containing ethanol ( $7.2 \%$ volume/volume, v/v; i.e. volume of ethanol intake/volume of total liquid intake) for a 7-day period. The ethanol solution was prepared daily and always presented at the same time of day (between 9 a.m. and 10 a.m.). Animals 


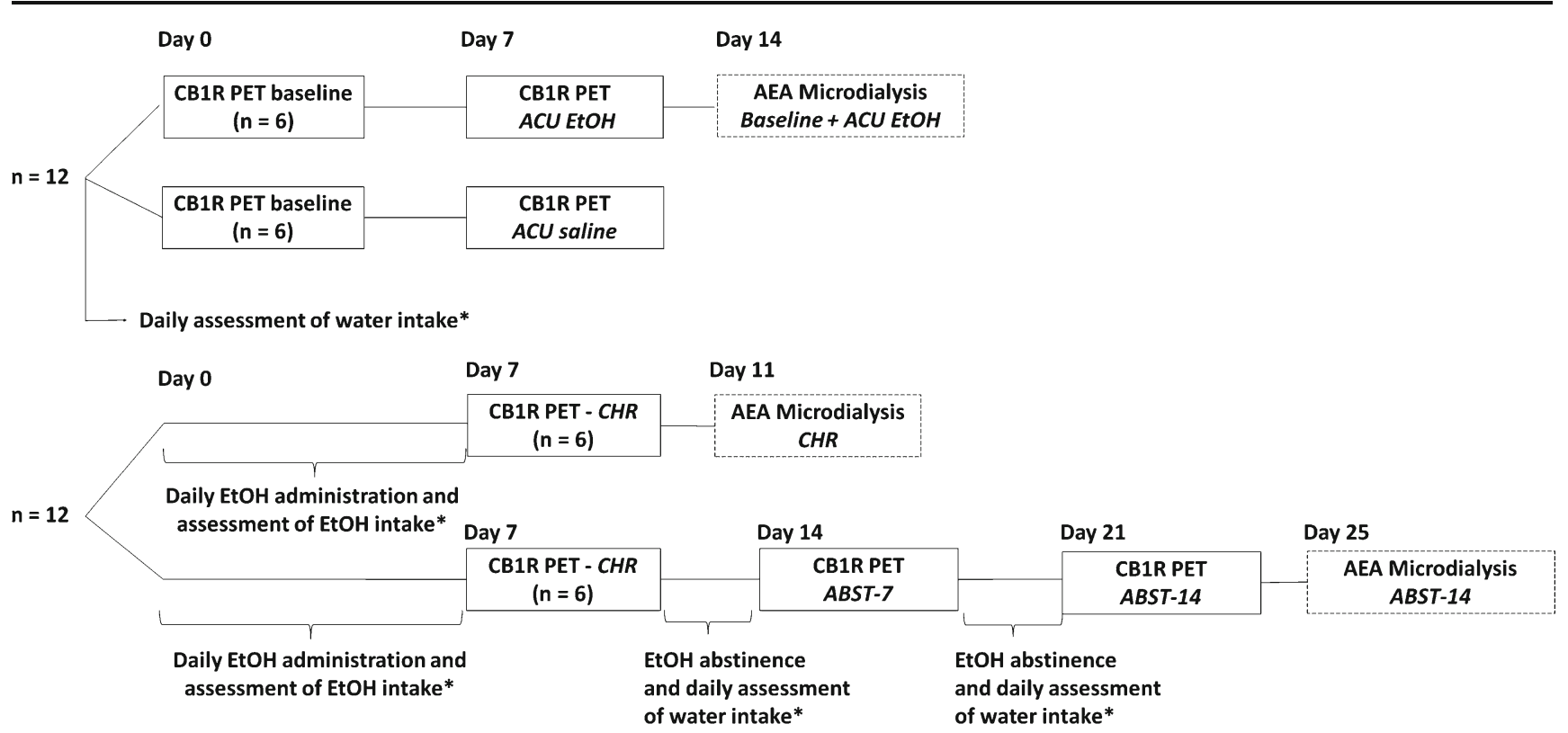

Fig. 1 Experimental design. $A C U$ acute ethanol administration, $C H R$ forced chronic ethanol administration, $A B S T-7$ ethanol abstinence for 7 days, ABST-14 ethanol abstinence for 14 days

had access to the ethanol solution during the whole day. To assess the effects of ethanol abstinence on CB1R binding in vivo, six of these animals were changed to drinking water alone on day 8 and monitored for a 2 -week period (Fig. 1). The body weight of the rats and liquid intake (expressed as millilitres per gram body weight) was recorded daily. In particular, cumulative and daily liquid intake were measured over a 7-day period prior to the PET scan for all the conditions (baseline, chronic and abstinence; Fig. 1).

\section{$\left[{ }^{18} \mathrm{~F}\right] \mathrm{MK}-9470$ characteristics and preparation}

CB1R imaging was done using the radioligand $\left[{ }^{18} \mathrm{~F}\right] \mathrm{MK}-9470$ ( $N$-[2-(3-cyano-phenyl)-3-(4-(2-[ $\left.{ }^{18} \mathrm{~F}\right]$ fluoroethoxy)phenyl)1-methylpropyl]-2-(5-methyl-2-pyridyloxy)-2-methyl proponamide), which is an inverse agonist with high affinity (rat $\mathrm{IC}_{50} 0.9 \mathrm{nM}$ ) and selectivity for the CB1R [19]. The precursor for the synthesis of $\left[{ }^{18} \mathrm{~F}\right] \mathrm{MK}-9470$ was obtained from Merck Research Laboratories (MRL, West Point, PA) and labelling was performed on-site using $2-\left[{ }^{18} \mathrm{~F}\right]$ fluoroethylbromide. Tracer preparation and characteristics have been described previously [18]. The final product was obtained after highperformance liquid chromatography (HPLC) purification and had a radiochemical purity of $>95 \%$. The tracer was administered in a sterile solution of $5 \mathrm{mM}$ sodium acetate buffer $(\mathrm{pH}$ 5.5) containing $6 \%$ ethanol.

\section{Small-animal PET imaging}

The rats used for assessment of the acute effects of ethanol were imaged on day 0 in the baseline condition and on day 7 upon acute exposure to ethanol or saline (Fig. 1). Acquisitions in the chronic ethanol condition were performed on day 7 , whereas the effects of ethanol abstinence were monitored after a 7-day and a 14-day period of abstinence in the same animals (Fig. 1). Prior to small-animal PET imaging, rats were anaesthetized using $2.5 \%$ isoflurane in $2.0 \mathrm{l} / \mathrm{min}$ oxygen for all conditions. On average, $12.0 \pm 3.7$ $\mathrm{MBq}$ of $\left[{ }^{18} \mathrm{~F}\right] \mathrm{MK}-9470$ (specific activity range $95-253$ $\mathrm{GBq} / \mu \mathrm{mol}$, mass dose per body weight $0.50 \pm 0.22 \mathrm{nmol} / \mathrm{kg}$ ) was injected into a tail vein using an infusion needle set. Body temperature was maintained between 36.5 and $37{ }^{\circ} \mathrm{C}$ with a heating pad during acquisition. After an overnight fast, $\left[{ }^{18} \mathrm{~F}\right] \mathrm{MK}-9470$ measurements were acquired for $20 \mathrm{~min}$ starting $1 \mathrm{~h}$ after injection [20].

Small-animal PET imaging was performed using an LSO detector-based FOCUS-220 tomograph (Siemens/Concorde Microsystems, Knoxville, TN) which has a transaxial resolution of $1.35 \mathrm{~mm}$ full-width at half-maximum. Data were acquired in a $128 \times 128 \times 95$ matrix with a pixel width of $0.475 \mathrm{~mm}$ and a slice thickness of $0.815 \mathrm{~mm}$. Sinograms were reconstructed using filtered back-projection.

In vivo microdialysis

After small-animal PET imaging, rats in the different ethanol conditions, i.e. acute, chronic and 14-day abstinence, were subjected to in vivo microdialysis of the brain in order to obtain quantitative measurements of the endogenous levels of AEA in the NAcc and these concentrations were correlated with regional $\mathrm{CB} 1 \mathrm{R}$ binding. Microdialysis was performed 4 days after small-animal PET imaging 
(Fig. 1). Rats in the chronic ethanol and abstinence groups were therefore kept in these conditions for 4 days extra. Prior to study setup, we verified that CB1R binding did not significantly differ between a longer exposure period (14 days) and the 7-day period of chronic ethanol consumption used for small-animal PET imaging, in order to avoid potential time-dependent confounders (CB1R measured in terms of standardized uptake value, SUV: global $\mathrm{SUV}_{7 \text {-days }}=1.1 \pm 0.2$; global $\mathrm{SUV}_{14 \text {-days }}=1.1 \pm 0.1$; not significantly different; $n=4$ ).

For microdialysis, rats were anaesthetized using a mixture of ketamine $\left(60 \mathrm{mg} / \mathrm{kg}\right.$ IP Ketalar ${ }^{\circledR}$; Pfizer, Brussels, Belgium) and medetomidine $\left(0.4 \mathrm{mg} / \mathrm{kg}\right.$, Dormitor ${ }^{\circledR}$; Pfizer $)$ and placed on a stereotaxic frame. The skull was exposed and a burr hole was drilled to implant a guide cannula (MAB 2/6/9.14.IC; Microbiotech/se AB, Stockholm, Sweden) above the right NAcc according to the atlas of Paxinos and Watson [21]. The coordinates used relative to the bregma are: lateral $-0.8 \mathrm{~mm}$, anterior $+1.6 \mathrm{~mm}$ and ventral $-5.7 \mathrm{~mm}$. These coordinates are the same as those previously used to evaluate the effects of an ethanol challenge injection [6], drug selfadministration [11] and acute administration of ethanol [4] on interstitial endocannabinoid levels in the NAcc.

After surgery, a probe (MAB 6.14.2; Microbiotech/se AB) with a membrane length of $2 \mathrm{~mm}$ and a molecular weight cutoff value of $15 \mathrm{kDa}$ was introduced via the cannula. The probe was perfused with Ringer's solution containing $147 \mathrm{mM}$ $\mathrm{NaCl}, 4 \mathrm{mM} \mathrm{KCl}, 1.1 \mathrm{mM} \mathrm{CaCl} 2$ and $10 \%(\mathrm{w} / \mathrm{v})$ hydroxypropyl- $\beta$-cyclodextrin $(\mathrm{HB}-\beta-\mathrm{CD})$ at a constant flow rate of $0.6 \mu \mathrm{l} / \mathrm{min}$. Inclusion of $\mathrm{HB}-\beta-\mathrm{CD}$ in the perfusate has been proven to substantially increase the dialysis recovery of endocannabinoids $[4,6,11,22,23]$. Animals were allowed to recover from surgery overnight and dialysate collection was started the next day. Samples were collected every $20 \mathrm{~min}$, yielding $12 \mu \mathrm{l}$ of dialysate. Rats used for assessment of acute effects were sampled over a baseline period of $120 \mathrm{~min}$ and for $240 \mathrm{~min}$ following an acute IP administration of $4 \mathrm{~g}$ of ethanol $/ \mathrm{kg}$ of body mass. Rats used for assessment of the effects of chronic ethanol exposure and abstinence were both monitored for a period of $120 \mathrm{~min}$ without any intervention. Dialysate samples were frozen immediately following collection and stored at $-80^{\circ} \mathrm{C}$ until analysis for AEA content using HPLC with tandem mass spectrometry (MS/MS) detection as described below.

Before injection on HPLC, $4 \mu \mathrm{l}$ of an internal standard solution, containing $2.5 \times 10^{-8} \mathrm{M}$ D8-AEA, was added to each sample. Calibration and quality control samples were prepared in the same way as the collected samples. Samples were injected into the HPLC system by an automated sample injector (SIL-30ADvp; Shimadzu, Japan). Chromatographic separation was performed on a GL Sciences Intersil Ph3.0 $100 \times 2.1 \mathrm{~mm}$ (3.0 $\mu \mathrm{m}$ particle size) held at a temperature of $45{ }^{\circ} \mathrm{C}$. Components were separated using a gradient from $\mathrm{A}$ to $\mathrm{B}$
(A $0.2 \% \mathrm{ACN}$ in $99.8 \% \mathrm{MilliQ}+0.1 \%$ formic acid; $B 90 \%$ ACN in $10 \%$ MilliQ $+0.1 \%$ formic acid) at a total flow rate of $0.25 \mathrm{ml} / \mathrm{min}$. MS analysis was performed using an API 5000 MS/MS system consisting of an API $5000 \mathrm{MS} / \mathrm{MS}$ detector and a Turbo Ion Spray interface. The acquisitions were performed in positive ionization mode, with ionization spray voltage set at $5.5 \mathrm{kV}$ and a probe temperature of $500{ }^{\circ} \mathrm{C}$. The instrument was operated in multiple reaction monitoring (MRM) mode.

Calibration curves (peak area ratio of analyte/internal standard concentration) were fitted using weighted $(1 / x)$ regression, and the sample concentrations were determined using the calibration curves. Calibration samples at the following concentrations were used: 0.01, 0.02, 0.05, 0.10, 0.20, 0.50, 1.00, $2.00,5.00,10.0$ and $15.0 \mathrm{nM}$. Accuracy was verified by quality control samples after each sample series. The concentrations of the quality control samples were $0.15,1.5$ and $12 \mathrm{nM}$. All sample concentrations were calculated with the Analyst data system (Applied Biosystems, version 1.4.2; The Netherlands) and averaged over the acquisition interval.

\section{Small-animal PET processing and analysis}

Images of $\left[{ }^{18} \mathrm{~F}\right] \mathrm{MK}-9470$ binding based on SUVs (SUV $=$ activity concentration in megabecquerels per millilitre $x$ body mass in grams/injected dose in megabecquerels) were generated as a measure of absolute CB1R binding. The use of SUV is justified given that (1) SUV modestly correlates with estimates of total distribution volume, as determined by full kinetic modelling in rats $\left(R^{2}=0.26-0.33\right)$ [19], while (2) full kinetic modelling in rats still hampers serial small-animal PET studies over time. We also investigated relative $\left[{ }^{18} \mathrm{~F}\right] \mathrm{MK}-9470$ binding when no absolute changes were noted by normalization to the global cerebral SUV.

To obtain the maximal use of information without a priori knowledge, PET data were analysed voxel-wise using SPM8 (Statistical Parametric Mapping; Wellcome Department of Cognitive Neurology, London, UK). For spatial normalization, individual PET data were normalized to a custom-made rat brain $\left[{ }^{18} \mathrm{~F}\right] \mathrm{MK}-9470$ template in Paxinos stereotactic space [24]. This methodology allows results to be reported in coordinates directly corresponding to the Paxinos coordinate system for the rat brain.

For SPM analysis, data were smoothed with an isotropic gaussian kernel of $1.2 \mathrm{~mm}$ and analysed in a multisubject $\times$ multifactor design using treatment (ethanol vs. saline) $\times$ conditions (baseline vs. acute) for assessment of the acute effects of ethanol, and in a multisubject design alone for the evaluation of the chronic exposure and abstinence conditions.

For statistical analysis, T-maps were interrogated at a peak voxel level of $p_{\text {height }}=0.005$ (uncorrected) and extent threshold $k_{\mathrm{E}}>200$ voxels. Only significant clusters with $p_{\text {cluster }}<0.05$ (corrected for multiple comparisons) were retained, in combination with sufficient localizing power 
( $p_{\text {height }}<0.005$, uncorrected for multiple comparisons), as described previously $[20,25]$. Exceptions on $p_{\text {cluster }}$ were made for clusters which were both neurobiologically plausible and relevant in the light of other findings in this study, and explicitly mentioned. To correct for multiple comparisons, we conducted a Monte Carlo simulation implemented using AlphaSim in the software package AFNI. Results of AlphaSim indicated a voxel-wise threshold of $p<0.005$ combined with a minimum cluster size of 200 voxels for the whole brain to ensure that family-wise error was kept below $5 \%$. For analysis of relative CB1R binding, proportional scaling to the mean voxel value was used and an analysis threshold of 0.8 of the mean image intensity was applied.

In addition, a voxel-based correlation analysis between relative $\mathrm{CB} 1 \mathrm{R}$ binding and the following covariates was performed in the ethanol-treated groups: (1) AEA content in the NAcc, and (2) daily ethanol consumption.

\section{Statistical analysis}

Conventional statistics were determined using GraphPad Prism v5.0 (San Diego, CA). Reported values are given as means \pm SD. Significance was defined at the $95 \%$ probability level $(p<0.05)$. Body weight, liquid intake and AEA content were analysed using nonparametric Kruskal-Wallis and Wilcoxon signed ranks test for assessment of the effects of acute and chronic ethanol exposure, respectively. The Dunn test was used for post hoc comparisons.

\section{Results}

\section{Ethanol consumption}

Total liquid consumption over a 7-day period prior to the PET scan did not significantly differ between the chronically ethanolexposed and ethanol-withdrawn rats as compared to baseline. The voluntary daily liquid intakes (means \pm SD) were $102 \pm 18$, $122 \pm 17$ and $117 \pm 15 \mathrm{ml} / \mathrm{g}$ for chronically exposed rats and the 7 day and 14-day abstinence rats, respectively, while baseline animals had an average daily water consumption of $114 \pm$ $5.8 \mathrm{ml} / \mathrm{g}$. Total liquid intake over a 7-day period prior to the PET scan also did not differ between the different conditions.

The amounts of liquid diet consumed by the chronically exposed rats resulted in a daily ethanol consumption of $5.47 \pm$ $0.59 \mathrm{~g} / \mathrm{kg}$ body weight.

In contrast, compared to the baseline condition, body weight at the start of the scan was significantly higher in the 7-day and 14-day abstinence rats because of the longer follow-up period $(370 \pm 27 \mathrm{~g}$ and $402 \pm 30 \mathrm{~g}$ vs. $321 \pm 22 \mathrm{~g}$, respectively; $p<0.05$ Dunn's post hoc test). Liquid intake measurements and body weights are shown for the different conditions in Table 1.
Effects of acute and chronic ethanol administration and ethanol abstinence on CB1R binding

Acute ethanol administration IP at a dose of $4 \mathrm{~g} / \mathrm{kg}$ of body mass did not result in absolute changes, but resulted in a significant increase in relative CB1R binding in the NAcc bilaterally as compared to controls with saline treatment. The level of increase at the Paxinos coordinate peak maximum $(x, y, z)=(1.4 ; 2.0 ;-8.4)$ was $7.7 \pm 1.5 \% \quad\left(p_{\text {height }}=\right.$ 4.5.10 ${ }^{-6}$; Fig. 2a, Table 2). No other areas of significant CB1R binding changes were found.

In contrast, chronic exposure to ethanol resulted in a significant decrease in relative $\mathrm{CB} 1 \mathrm{R}$ binding compared to the baseline condition in the right hippocampus $(-5.2 \pm 3.1 \%$; $p_{\text {height }}=1.0 \times 10^{-4}$ ) and in a cluster covering the right caudate-putamen, insular cortex and primary sensory cortex $\left(-5.7 \pm 3.2 \% ; p_{\text {height }}=7.3 \times 10^{-5}\right)$. When comparing relative CB1R binding for the 7-day and 14-day abstinence conditions to the baseline condition, the same regions were involved, although the CB1R changes were more pronounced in those rats that had abstained longer from consuming ethanol. Relative CB1R binding increased in the bilateral hippocampus and caudate-putamen by $+8.9 \%$ (SD $1.5 \%$; $p_{\text {height }}=$ $\left.2.4 \times 10^{-5}\right)$ and $+14.2 \%\left(\right.$ SD $\left.1.6 \% ; p_{\text {height }}=1.6 \times 10^{-6}\right)$ at the Paxinos coordinate peak maximum for the 7-day and 14day abstinence conditions, respectively, when compared to the baseline condition. Relative CB1R binding also decreased in these conditions in clusters comprising the bilateral frontal and orbital cortices by $-20.1 \%\left(\mathrm{SD} 1.3 \%\right.$; $\left.p_{\text {height }}=6.0 \times 10^{-6}\right)$ and $-34.3 \%$ (SD $1.2 \%$; $p_{\text {height }}=4.2 \times 10^{-6}$; Fig. 3, Table 2). Note that similar findings of increased binding in the caudateputamen and hippocampus were observed when comparing the 14-day abstinence and the chronic exposure conditions (+ $7.2 \pm 3.5 \%$; $p_{\text {height }}=2.8 \cdot 10^{-5}$ ). Detailed cluster peak locations and $p$-values from the relative voxel-based analyses are shown in Table 2.

Analysis of absolute CB1R binding values in the chronic and abstinence conditions did not reveal any significant difference in regional SUVs following chronic ethanol exposure compared to baseline, but showed relative differences in the hippocampus and caudate-putamen following 14 days of abstinence $\left(+33.3 \pm 3.9 \%\right.$; $p_{\text {height }}=$ $8.7 \times 10^{-5}$ ). Also, absolute CB1R binding did not significantly differ between the 7-day abstinence condition and baseline.

Effects of acute and chronic ethanol exposure and ethanol abstinence on AEA levels

The measured baseline mean level of AEA in the NAcc was $0.24 \pm 0.16 \mathrm{nM}$ (range $0.10-0.55 \mathrm{nM}$ ). Intraperitoneal acute ethanol administration at a dose of $4 \mathrm{~g} / \mathrm{kg}$ of body mass led to a significant increase in AEA levels $(0.43 \pm 0.20 \mathrm{nM}$; + 
Table 1 Liquid intake and body weight measured in rats with forced access to $7.2 \%$ ethanol (v/v) or water

\begin{tabular}{llllll}
\hline & Baseline $(n=12)$ & Acute $(n=12)$ & Chronic & Abstinence \\
\cline { 4 - 6 } & & & 7 days $(n=12)$ & 7 days $(n=6)$ & Water \\
\hline Liquid diet & Water & - & Ethanol & Water \\
Body weight $(\mathrm{g})$ & $321 \pm 22$ & $350 \pm 28$ & $340 \pm 14$ & $370 \pm 27^{*}$ & $402 \pm 30^{*}$ \\
Daily liquid intake $(\mathrm{ml} / \mathrm{g})$ & $114 \pm 5.8^{\mathrm{a}}$ & - & $102 \pm 18$ & $122 \pm 17$ & $117 \pm 15$ \\
Cumulative liquid intake $(\mathrm{ml} / \mathrm{g})$ & $685 \pm 79^{\mathrm{a}}$ & - & $717 \pm 78$ & $733 \pm 74$ & $704 \pm 71$ \\
\hline
\end{tabular}

Data were analysed using non-parametric Kruskal-Wallis test with Dunn's post hoc test. Data are expressed as means \pm SD. Body weight was measured at the start of the PET scan. Cumulative and daily liquid intakes were measured over a 7-day period prior to PET.

${ }^{*} p<0.05$, compared to baseline condition

${ }^{\mathrm{a}} n=6$

$102 \pm 71 \% ; p=0.03)$. In contrast, compared to the baseline condition, AEA levels in the NAcc were not significantly different following chronic ethanol exposure $(0.18 \pm$ $0.08 \mathrm{nM} ; p>0.05)$ or following 14 days of abstinence $(0.21 \pm 0.08 \mathrm{nM} ; p>0.05)$. The effects of acute and chronic ethanol exposure and abstinence on AEA levels in the NAcc are also shown in Fig. 2 b.

a
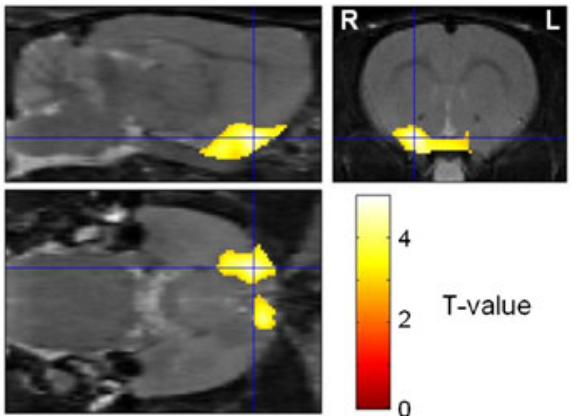

C

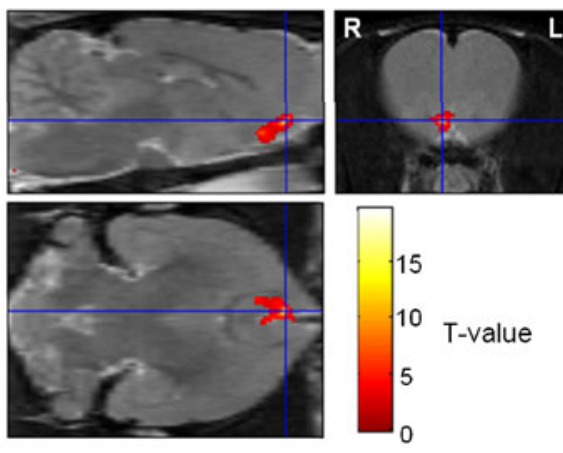

Fig. 2 a, c Statistical parametric maps of a the increase in relative $\left[{ }^{18} \mathrm{~F}\right] \mathrm{MK}-9470$ binding in the bilateral NAcc of healthy rats upon acute exposure to ethanol as compared to saline treatment, and of $\mathbf{c}$ relative $\left[{ }^{18} \mathrm{~F}\right] \mathrm{MK}-9470$ binding correlated to AEA content in the NAcc. Differences in the brain regions are colour-coded and are superimposed on the MRI template in three orthogonal planes. The coloured bars on the right express T-score levels. b Change in AEA content in the NAcc
Correlation between ethanol-induced changes in AEA levels and CB1R binding

Based on the fact that acute ethanol administration led to an increase in relative $\mathrm{CB} 1 \mathrm{R}$ binding in the NAcc bilaterally, we evaluated the correlation between these receptor changes and the AEA levels measured in that region. Voxel-based correlation

b

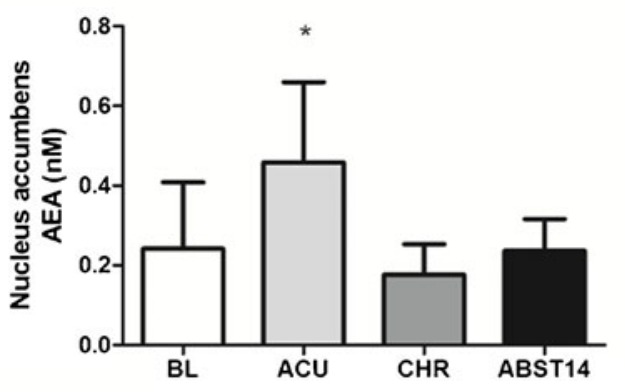

d

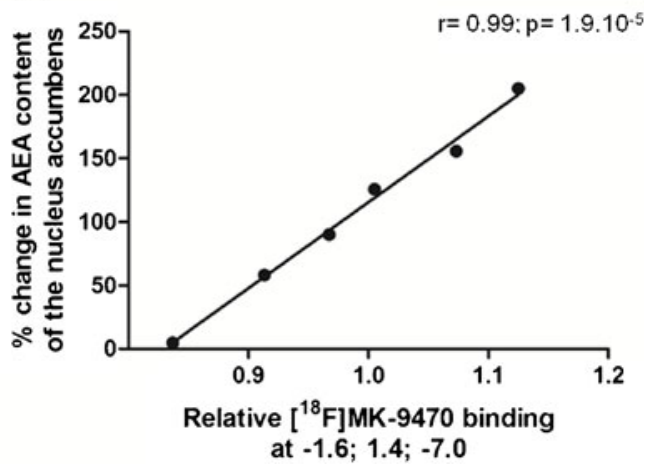

following acute ethanol exposure $(A C U)$, chronic ethanol exposure $(C H R)$, and a 14-day abstinence period from ethanol (ABST14), as compared to the baseline condition $(B L)$. d Scatter plot of relative $\left[{ }^{18} \mathrm{~F}\right] \mathrm{MK}-9470$ binding at the maximal peak location of the NAcc in relation to AEA change following acute ethanol exposure. ${ }^{*} p<0.05$, Wilcoxon signed ranks test 
Table 2 Peak locations for the clusters in the group comparisons of relative CB1R binding

\begin{tabular}{|c|c|c|c|c|c|c|c|c|c|}
\hline & \multicolumn{2}{|c|}{ Cluster level } & \multicolumn{3}{|c|}{ Voxel level } & \multicolumn{3}{|c|}{ Structure $^{\mathrm{g}}$} & \multirow[t]{2}{*}{ Brain region } \\
\hline & $p_{\text {corr }}^{\mathrm{b}}$ & $k_{\mathrm{E}}^{\mathrm{c}}$ & $T^{\mathrm{d}}$ & $p_{\text {uncorr }}^{\mathrm{e}}$ & $\begin{array}{l}\text { Intensity } \\
\text { difference }(\%)^{\mathrm{f}}\end{array}$ & $x$ & $y$ & $z$ & \\
\hline \multicolumn{10}{|c|}{ Baseline vs. acute exposure } \\
\hline \multirow[t]{2}{*}{$\begin{array}{c}\Delta\left(\mathrm{BL}-\mathrm{ACU}_{\mathrm{EtOH}}\right)> \\
\Delta\left(\mathrm{BL}-\mathrm{ACU}_{\text {saline }}\right)^{\mathrm{a}}\end{array}$} & \multirow[t]{2}{*}{0.001} & \multirow[t]{2}{*}{2379} & $\begin{array}{l}4.98 \\
4.80\end{array}$ & $\begin{array}{l}<0.001 \\
<0.001\end{array}$ & \multirow[t]{2}{*}{+9.28} & $\begin{array}{r}1.4 \\
-2.4\end{array}$ & $\begin{array}{l}2.0 \\
1.4\end{array}$ & $\begin{array}{l}-8.4 \\
-8.8\end{array}$ & \multirow[t]{2}{*}{ Bilateral nucleus accumbens } \\
\hline & & & 4.24 & $<0.001$ & & -1.8 & 1.2 & -10.0 & \\
\hline \multicolumn{10}{|c|}{ Baseline vs. chronic exposure } \\
\hline \multirow[t]{3}{*}{$\mathrm{CHR}<\mathrm{BL}$} & 0.013 & 1771 & $\begin{array}{l}4.62 \\
4.38\end{array}$ & $\begin{array}{l}<0.001 \\
<0.001\end{array}$ & -5.73 & $\begin{array}{l}-5.2 \\
-3.5\end{array}$ & $\begin{array}{l}0.0 \\
0.4\end{array}$ & $\begin{array}{l}-5.0 \\
-2.4\end{array}$ & $\begin{array}{l}\text { Right caudate-putamen, insular } \\
\text { cortex and primary sensory } \\
\text { cortex }\end{array}$ \\
\hline & \multirow[t]{2}{*}{0.362} & 598 & $\begin{array}{l}3.71 \\
3.39\end{array}$ & $\begin{array}{l}<0.001 \\
<0.001\end{array}$ & \multirow[t]{2}{*}{-5.17} & $\begin{array}{l}-5.8 \\
-3.8\end{array}$ & $\begin{array}{l}-5.6 \\
-5.8\end{array}$ & $\begin{array}{l}-4.4 \\
-3.2\end{array}$ & \multirow[t]{2}{*}{ Right hippocampus } \\
\hline & & & 3.32 & $<0.001$ & & -4.2 & -6.0 & -5.0 & \\
\hline \multicolumn{10}{|l|}{ Baseline vs. abstinence } \\
\hline \multirow[t]{2}{*}{ 7-day abstinence $<$ BL } & \multirow[t]{2}{*}{$<0.001$} & \multirow[t]{2}{*}{2788} & $\begin{array}{l}7.98 \\
7.74\end{array}$ & $\begin{array}{l}<0.001 \\
<0.001\end{array}$ & \multirow[t]{2}{*}{-20.14} & $\begin{array}{l}0.4 \\
1.4\end{array}$ & $\begin{array}{l}2.8 \\
4.2\end{array}$ & $\begin{array}{l}-6.6 \\
-5.0\end{array}$ & \multirow[t]{2}{*}{$\begin{array}{l}\text { Bilateral frontal cortex and } \\
\text { orbital cortex (ventral part) }\end{array}$} \\
\hline & & & 7.73 & $<0.001$ & & -0.8 & 4.8 & -5.0 & \\
\hline \multirow[t]{3}{*}{$\begin{array}{l}\text { 7-day abstinence }> \\
\text { baseline }\end{array}$} & \multirow[t]{2}{*}{0.004} & \multirow[t]{2}{*}{1521} & $\begin{array}{l}6.79 \\
6.27\end{array}$ & $\begin{array}{l}<0.001 \\
<0.001\end{array}$ & \multirow[t]{2}{*}{+8.86} & $\begin{array}{l}-3.4 \\
-2.2\end{array}$ & $\begin{array}{l}-3.0 \\
-3.0\end{array}$ & $\begin{array}{l}-3.6 \\
-2.4\end{array}$ & \multirow[t]{2}{*}{ Bilateral hippocampus } \\
\hline & & & 5.79 & $<0.001$ & & 0.5 & -2.5 & -2.5 & \\
\hline & 0.170 & 612 & 6.50 & $<0.001$ & +5.02 & -1.2 & 0.4 & -3.4 & Right caudate-putamen \\
\hline \multirow[t]{2}{*}{$\begin{array}{l}\text { 14-day abstinence } \\
<\text { baseline }\end{array}$} & \multirow[t]{2}{*}{0.003} & \multirow[t]{2}{*}{1618} & $\begin{array}{l}9.01 \\
6.65\end{array}$ & $\begin{array}{l}<0.001 \\
<0.001\end{array}$ & \multirow[t]{2}{*}{-34.30} & $\begin{array}{r}1.8 \\
-0.8\end{array}$ & $\begin{array}{l}4.8 \\
5.2\end{array}$ & $\begin{array}{l}-5.6 \\
-5.2\end{array}$ & \multirow[t]{2}{*}{$\begin{array}{l}\text { Bilateral prefrontal cortex and } \\
\text { orbital cortex (lateral part) }\end{array}$} \\
\hline & & & 5.66 & $<0.001$ & & 1.0 & 5.6 & -6.6 & \\
\hline \multirow[t]{2}{*}{$\begin{array}{l}\text { 14-day abstinence> } \\
\text { baseline }\end{array}$} & \multirow[t]{2}{*}{$<0.001$} & 7900 & $\begin{array}{r}10.07 \\
7.54\end{array}$ & $\begin{array}{l}<0.001 \\
<0.001\end{array}$ & +14.16 & $\begin{array}{l}2.0 \\
3.8\end{array}$ & $\begin{array}{r}0.8 \\
-2.4\end{array}$ & $\begin{array}{l}-4.8 \\
-3.8\end{array}$ & $\begin{array}{l}\text { Bilateral caudate-putamen } \\
\text { and hippocampus }\end{array}$ \\
\hline & & & 7.34 & $<0.001$ & & -1.8 & -3.0 & -3.0 & \\
\hline
\end{tabular}

$T$-maps were interrogated at a peak voxel level of $p_{\text {height }}=0.005$ (uncorrected) and extent threshold $k_{\mathrm{E}}>200$ voxels

${ }^{\mathrm{a}} \Delta\left(\mathrm{BL}-\mathrm{ACU}_{\mathrm{EtOH}}\right)$ : difference in relative $\left[{ }^{18} \mathrm{~F}\right] \mathrm{MK}-9470$ binding following acute exposure to ethanol as compared to baseline condition. $\Delta\left(\mathrm{BL}-\mathrm{ACU}_{\text {saline }}\right)$ : difference in relative $\left[{ }^{18} \mathrm{~F}\right] \mathrm{MK}-9470$ binding following acute exposure to saline as compared to baseline condition

${ }^{\mathrm{b}} p_{\text {corr }}$ the chance $(p)$ of finding a cluster with this or a greater size $\left(k_{\mathrm{E}}\right)$, corrected for search volume

${ }^{\mathrm{c}} k_{\mathrm{E}}$ cluster extent

${ }^{\mathrm{d}} T$ measure of statistical significance

${ }^{\mathrm{e}} p_{\text {uncorr }}$ the chance $(p)$ of finding (under the null hypothesis) a voxel with this or a greater height ( $T$-statistic), uncorrected for search volume

${ }^{\mathrm{f}}$ Intensity difference (\%) at the voxel level in comparison to controls

${ }^{\mathrm{g}} x$ lateral distance in millimetres from the midline (negative values to the right side), $y$ anteroposterior location relative to Bregma (negative values posterior to Bregma), $z$ dorsoventral position (based upon the Paxinos stereotactic atlas)

analyses showed a positive relationship between the change in AEA level following acute ethanol exposure and relative CB1R binding. After correction for the small volume of the NAcc (sphere of $2 \mathrm{~mm}$ at $(x, y, z)=(-1.6 ; 1.4 ;-7.0)$, this cluster reached significance $\left(r=0.99 ; p_{\text {height }}=1.9 .10^{-5}\right.$; Fig. 2 d, Table 3$)$.

Correlation between ethanol consumption and CB1R binding

We further assessed correlations between CB1R binding and ethanol consumption. After chronic ethanol exposure, no significant correlations between ethanol drinking parameters (daily and cumulative ethanol intake) and CB1R binding were found. Significant correlations were found between ethanol intake before abstinence and CB1R binding in the frontal cortex and hippocampus, as shown in Fig. 4. In particular, a negative relationship was found between daily ethanol consumption and the difference in relative CB1R binding in the 7-day abstinence condition and the baseline condition in the right frontal cortex, indicating a higher $\mathrm{CB} 1 \mathrm{R}$ binding decrease in rats with more previous ethanol intake at that time $\left(r=-0.99 ; p_{\text {height }}=1.2 \times 10^{-5}\right.$; Fig. $\left.4 a, b\right)$. 
Fig. 3 Coronal brain sections showing overlays on the regions where statistically significant increases (red) and decreases (blue) in relative $\left[{ }^{18} \mathrm{~F}\right] \mathrm{MK}-9470$ binding were observed following chronic ethanol exposure $(\mathrm{CHR})$, the 7 day abstinence period (ABST 7) and the 14-day abstinence period (ABST 14), as compared to baseline (figure given at $p_{\text {height }}<0.005$ uncorrected) Significance is indicated by the $T$ statistic colour scales, which correspond to the level of significance at the voxel level. The distance between the sections is $1.00 \mathrm{~mm}$ and the positions relative to the bregma (positive values for sections anterior to the bregma) are shown at the on top left corner of each section. Images are oriented according to neurological convention

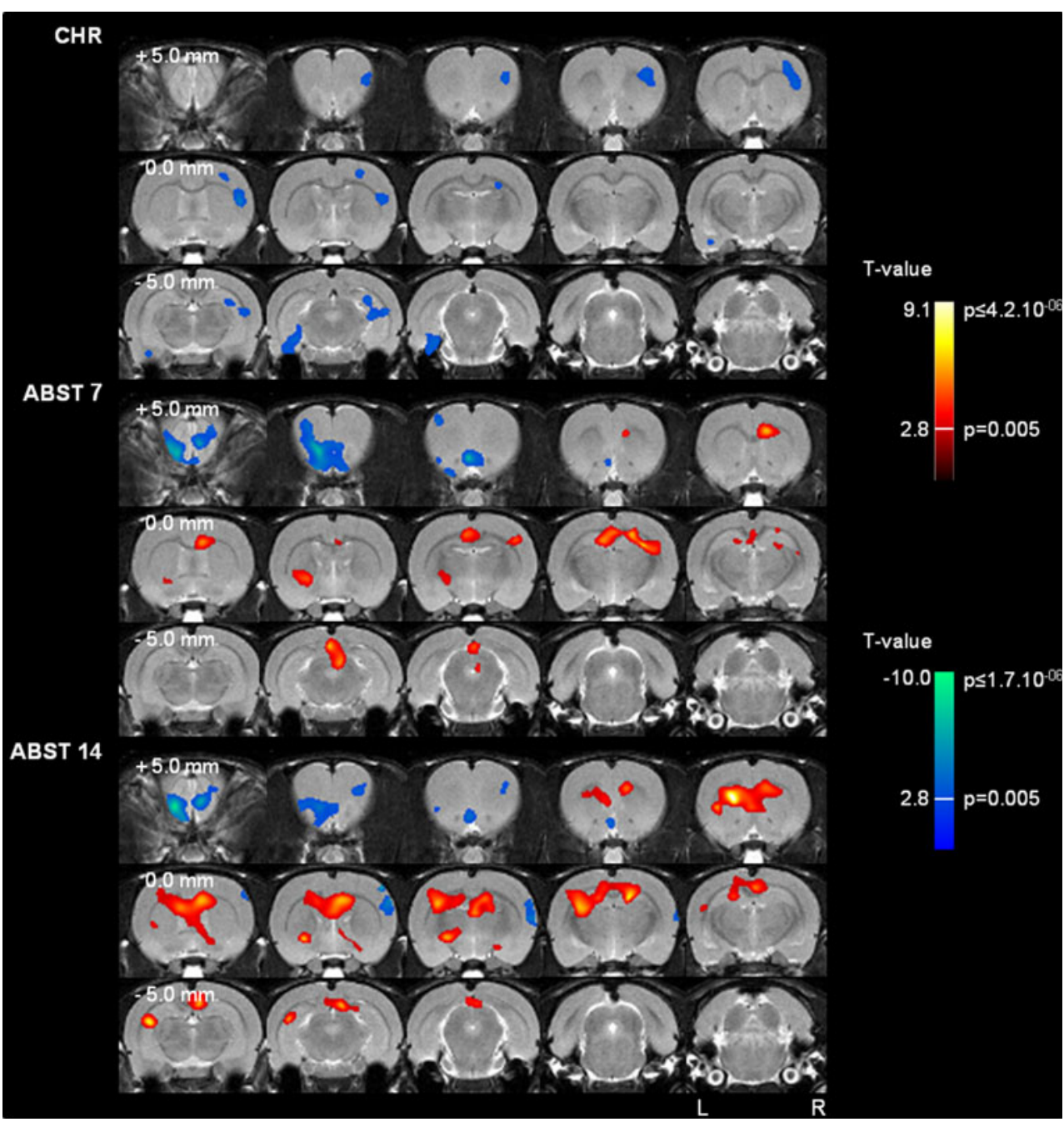

Additionally, daily ethanol intake was positively correlated with the difference in relative CB1R binding in the 14-day abstinence condition and the baseline condition in the left hippocampus $\left(r=0.99 ; p_{\text {height }}=2.3 \times 10^{-5}\right.$; Fig. $\left.4 \mathrm{c}, \mathrm{d}\right)$. Detailed cluster peak locations and $p$ values from the voxelbased analyses are shown in Table 3.

\section{Discussion}

In the present study, we characterized the changes in CB1R binding and levels of AEA in vivo in rats subjected to several ethanol conditions using $\left[{ }^{18} \mathrm{~F}\right] \mathrm{MK}-9470$ smallanimal PET and microdialysis.

Firstly, we provide preclinical evidence that acute exposure to ethanol is related to an increase in CB1R binding in the NAcc that is correlated with increases in AEA levels in that region (Fig. 2 and Table 2). This finding of increased levels of CB1R binding following acute ethanol exposure is consistent with PET findings in healthy humans, where acute ethanol administration has been shown for the first time to result in a transient increase in CB1R binding, including in the NAcc [17]. In contrast, other preclinical studies have shown no changes in the levels of CB1Rs in the hypothalamus and caudate-putamen [8] or in CB1R gene expression in the NAcc, while decreased CB1R gene expression has been shown in the caudate-putamen, amygdala and hypothalamic nucleus ex vivo within $2 \mathrm{~h}$ of a single intragastric administration of $3 \mathrm{~g} / \mathrm{kg}$ of ethanol [7]. The AEA content in the NAcc of rats has been reported to decrease within $60-90 \mathrm{~min}$ of IP administration of $2 \mathrm{~g} / \mathrm{kg}$ and $4 \mathrm{~g} / \mathrm{kg}$ of ethanol [4, 6], while ethanol selfadministration for $24 \mathrm{~h}$ did not induce any change [11]. Discrepancies between our findings and the results of previous preclinical studies may be because of methodological differences (e.g. in vivo CB1R imaging vs. ex vivo measurement of CB1R gene expression) or of different routes (e.g. IP vs. intragastric) and durations of ethanol administration. Discrepancies are probably not due to species differences as all experiments were performed in rats. 


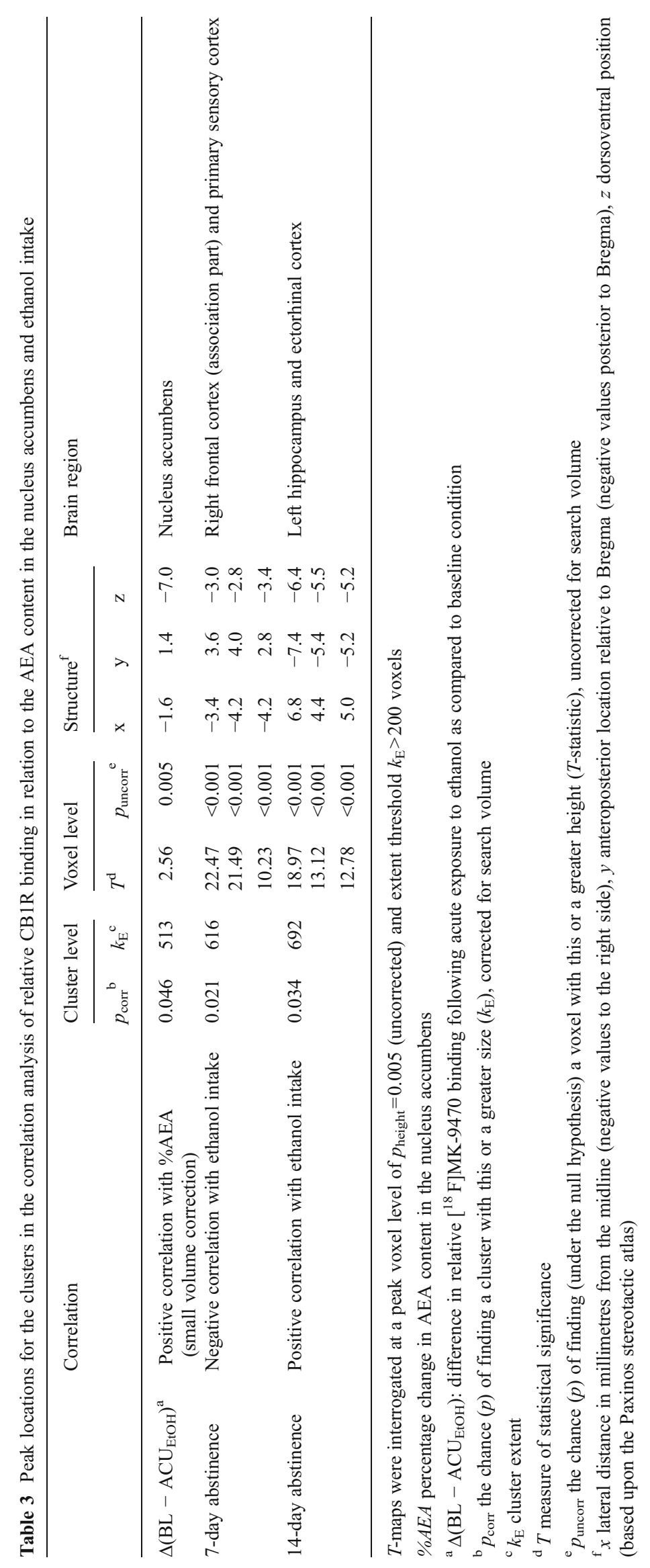


Fig. 4 a, c Results of voxelbased correlation analyses of the average daily ethanol consumption with the difference in relative $\left[{ }^{18} \mathrm{~F}\right] \mathrm{MK}$ 9470 binding after a the 7-day abstinence from ethanol (ABST-7) and $\mathbf{c}$ the 14-day abstinence from ethanol (ABST14), compared to the baseline condition. b, d Scatter plots of the differences in relative $\left[{ }^{18} \mathrm{~F}\right] \mathrm{MK}-9470$ binding at the maximal peak location in $\mathbf{b}$ the frontal cortex and $\mathbf{d}$ the hippocampus in relation to the average daily ethanol consumption. Significance is indicated by the $T$ statistic colour scales, which correspond to the level of significance at the voxel level. Images are oriented according to neurological convention a

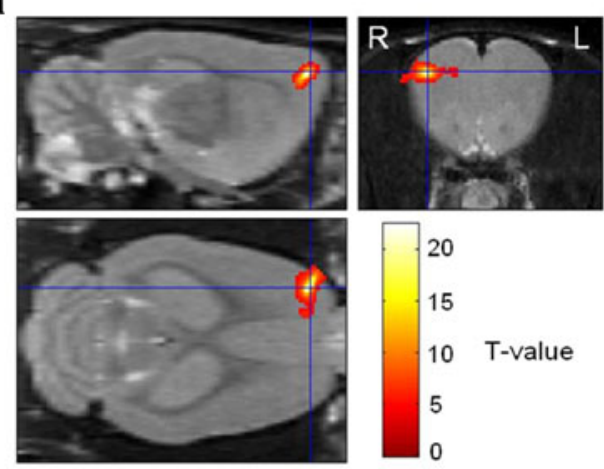

C

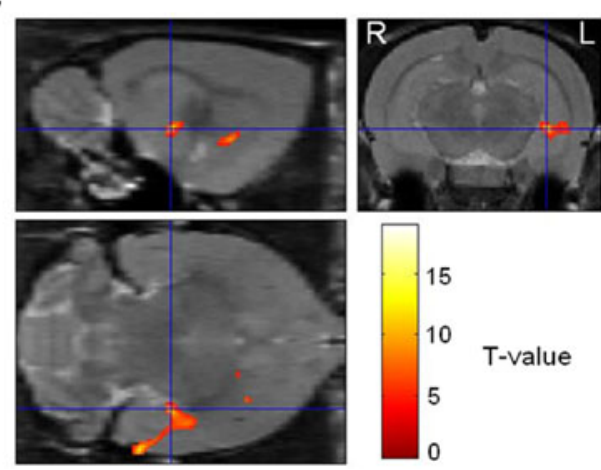

b

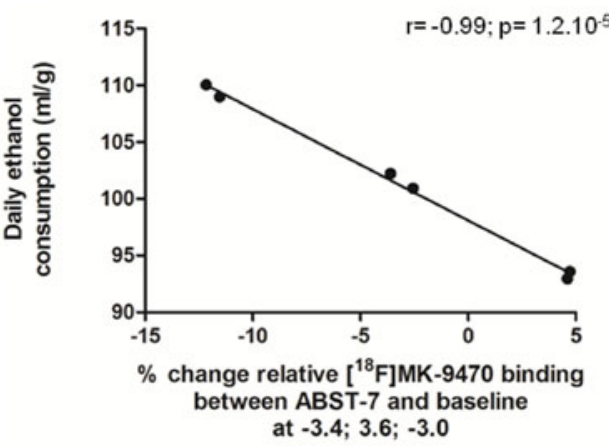

d

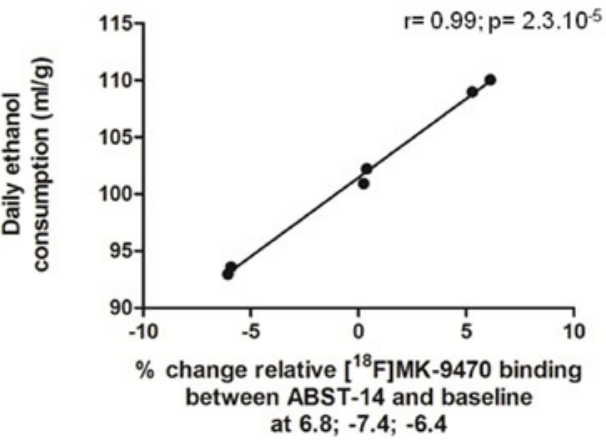

The mechanism by which ethanol promotes increased AEA levels in the NAcc on a short-term basis may be related to the impact of ethanol on levels of other endocannabinoids, such as 2-AG. In the NAcc, AEA regulates synaptic activity predominantly via transient receptor potential vanilloid 1 (TRPV1) receptors [26]. Maccarrone et al. [27] additionally found that increased AEA levels result in decreased 2-AG release via the stimulation of TRPV1 channels. Accumulating evidence suggests that 2-AG is a more suitable candidate than AEA as an endogenous CB1R ligand, at least in central synapses [28], and is therefore much more likely to cause rapid CB1R downregulation. Thus, it is conceivable that increased AEA levels may reduce tonic 2-AG levels, which may lead to an increase of CB1R binding. This scenario is also in accordance with the observation of Romero et al. who found that acute AEA administration resulted in a significant increase in CB1R density in the hippocampus [29]. However, from the current findings, it remains unclear whether changes in receptor binding are due to altered receptor density, or changes in receptor affinity or in receptor trafficking, as they cannot be distinguished with PET. Nevertheless, the increased CB1R binding cannot be due to a possible competition effect of endogenous cannabinoids with the $\left[{ }^{18} \mathrm{~F}\right] \mathrm{MK}-9470$ radioligand. The affinity of the endocannabinoids $(26-209 \mathrm{nM}$ for AEA and even above $10 \mu \mathrm{M}$ for $2-\mathrm{AG}$ ) is 100 -fold to 1,000 -fold lower than the nanomolar affinity of $\left[{ }^{18} \mathrm{~F}\right] \mathrm{MK}-9470(0.7 \mathrm{nM})$ for the CB1R [30]. To look at the status of a receptor without any influence of the endogenous ligand, high-affinity radioligands are necessary, as is the case with $\left[{ }^{18} \mathrm{~F}\right] \mathrm{MK}-9470$. Also, as demonstrated previously for $\left[{ }^{11} \mathrm{C}\right] \mathrm{MePPEP}$ [31], current high-affinity $\mathrm{CB} 1 \mathrm{R}$ radioligands are not displaceable in vivo by endogenous agonist or synthetic agonists.

Secondly, we provide preclinical evidence that 1 -week of chronic ethanol exposure leads to decreased CB1R binding in the hippocampus, caudate-putamen, and insular and primary sensory cortices as compared to the baseline condition (Fig. 3 and Table 2). The decreases in the hippocampus and caudate-putamen were reversible in the short-term, as observed after $1-2$ weeks of ethanol abstinence, and even recovered to levels above normal (Fig. 3 and Table 2). Reductions in CB1R binding in the hippocampus and caudate-putamen after chronic administration are in line with the findings of previous ex vivo work demonstrating decreased CB1R density, gene expression and functionality in these regions, and also in the hypothalamus, cortex and cerebellum following 3 days and 52 days of ethanol consumption, as measured using $\left[{ }^{3} \mathrm{H}\right] \mathrm{CP} 55,940$ autoradiography, in situ hybridization and $\left[{ }^{35} \mathrm{~S}\right] \mathrm{GTP}-\mathrm{S}$ binding assays $[10,13]$. Basavarajappa et al. additionally reported that these decreases in CB1R levels occur without any changes in receptor affinity [32]. Their recovery following withdrawal to levels above normal have so far only been demonstrated ex vivo in the hippocampus for CB1R gene expression and its signal transduction efficiency, whereas protein levels in this region reached only baseline values $[10,33]$. Also, in line with the findings of our work, Mitrirattanakul et al. 
found that the upregulation of hippocampal CB1Rs is highly dependent on the duration of alcohol withdrawal [33]. In the present study, recovery in the caudate-putamen and hippocampus was also higher following 14 days of abstinence than following 7 days, i.e. $+14 \%$ vs. $+7 \%$.

The findings discussed above are supported by the model recently proposed by Pava and Woodward on ECS changes during different stages of alcohol addiction [3]. They stated that chronic ethanol treatment is associated with reductions in $\mathrm{CB} 1 \mathrm{R}$ expression in most brain structures that are paralleled by increased concentrations of both AEA and 2-AG [33-37]. The hyperexcitability associated with the initial phase of withdrawal and abstinence (a few days) results in a large increase in endocannabinoid release and concomitant reductions in CB1R expression. Over time endocannabinoid levels may be persistently increased during several weeks of abstinence, and CB1R expression is upregulated over time to allow the ECS to respond to phasic changes. Although in the present study we did not quantify AEA levels in these regions, it seems from the above findings as if CB1R signalling specifically in the hippocampus and caudate-putamen of all brain regions plays a key role in ethanol addiction. Also in alcoholdependent patients, chronic alcohol consumption has been shown to result in a reduction in CB1R availability affecting the whole brain, although this reduction remained unaltered after 4 weeks of supervised abstinence from alcohol $[15,16]$. Nevertheless, recovery to normal levels has also been found to occur in chronic cannabis users upon cannabis abstinence using $\left[{ }^{18}\right.$ F]FMPEP- $\mathrm{d}_{2}$ [38].

Thirdly, in the current study, withdrawal of ethanol additionally resulted in decreased CB1R binding in the frontal cortex and in the orbitofrontal cortex as compared to the baseline condition (Fig. 3 and Table 2). It has previously been demonstrated that the ECS and the endovanilloid system interact within the rat prefrontal cortex to control anxietylike behaviour that is elicited by withdrawal of ethanol [39]. Blockade of the CB1R, either systemically or by local administration to the amygdala-prefrontal cortical pathway, strongly attenuates anxiogenic traits [40, 41]. Rubio et al. have suggested that this effect occurs through restoration of GABA/glutamate imbalances within the prefrontal cortex, primarily by modifying GABAergic transmission [41]. It therefore seems conceivable that the decrease in CB1R binding we found in the same region could have been an endogenous compensatory response. Of special interest, CB1Rdeficient mice appear to suffer no signs of withdrawal upon alcohol discontinuation [42]. However, results concerning the relationship between anxiety levels and alcohol drinking are still ambiguous, and we did not measure behavioural aspects of withdrawal in this study [43]. In human studies, decreased neuronal activity in the prefrontal, especially the orbitofrontal, cortex during detoxification has also been demonstrated using fMRI and $\left[{ }^{18} \mathrm{~F}\right]$ FDG PET [44].
Finally, we demonstrated that the frontal decrease in CB1R binding after 7 days of abstinence was inversely related to the history of daily ethanol consumption, indicating a greater decrease in those rats with greater previous ethanol intake (Fig. 4 and Table 3). We also found that chronic ethanol exposure decreased CB1R binding in the hippocampus that was found to be reversible after $1-2$ weeks of abstinence (Fig. 4 and Table 3). The magnitude of this hippocampal CB1R change at 2 weeks of abstinence was positively correlated with the average daily consumption of ethanol, suggesting a higher reversible effect with greater previous ethanol intake. It is worth mentioning that the positive correlation between ethanol consumption and CB1R binding in the hippocampus was also detectable following 7 days of abstinence and that the negative correlation between these two variables in the frontal cortex was also seen following 14 days of abstinence, albeit for both time points at a lower significance level than found in this work $\left(p_{\text {height }}<0.01, k_{\text {ext }}=200\right)$.

Several studies have posited common substrates of addiction related to the frontocortical and hippocampal regions, including cognitive control, delayed gratification and memory, suggesting a close relationship between brain circuits involved in the regulation of drug dependence and learning and memory $[45,46]$. Principally, hippocampal mechanisms provide the contextual background to drug craving that defines the motivational arousal upon which goal-directed responding occurs, while frontal mechanisms participate in executive control of the response [47]. CB1Rs control both hippocampal and frontal glutamatergic projections to the NAcc via a presynaptic inhibitory effect on neurons that release both GABA and cholecystokinin [47]. In line with our findings of decreased CB1R binding in the frontal cortex-and thus of reduced glutamatergic activity - positively related to ethanol consumption, lesions of the (pre)frontal cortex in rats have been shown to result in increased responding for cocaine under a second-order schedule of reinforcement and in enhanced acquisitions of cocaine self-administration [48]. Moreover, specific neurochemical profiles of the frontal cortex region have been shown to be significantly altered in the rat model of long-term alcohol consumption as compared to control rats [49]. In addition, in line with our findings of increased CB1R binding in the hippocampus - and thus of increased glutamatergic activity-negatively related to ethanol consumption, stimulation of the hippocampus has been shown to reinstate extinguished cocaine seeking in rats when animals were placed in a context of drug taking [50]. Moreover, the activation of hippocampal circuits in association with a drug-related context activates the prefrontal cortex in expectation of the drug reinforcer. Specifically, the attribution of salience to a given stimulus, which is a function of the frontal cortex, depends on the relative value of a reinforcer compared to simultaneously available reinforcers [51]. This requires knowledge of the strength of the stimulus as a 
reinforcer, which depends on the hippocampus. Additionally, preclinical studies have also shown that CB1Rs also play a critical role in modulating stress responses through actions in both the hippocampus and prefrontal cortex [52]. Therefore, it is not unlikely that frontal and hippocampal CB1R changes are related to the amount of ethanol consumed prior to abstinence.

In this study, we only correlated the ethanol-induced changes in CB1R binding to the endogenous levels of AEA changes. Most lipidomic studies investigating increases in AEA levels have also shown elevation of molecules closely related to endocannabinoids including palmitoyl ethanolamide and oleoyl ethanolamine. To investigate whether the effect of alcohol is selective for AEA indicating a truly specific upregulation of endocannabinoid signalling or whether it is a more general homeostatic response, further microdialysis experiments should include the monitoring of the levels of other endocannabinoids, including 2-AG, and investigation of the AEA levels in other brain regions. In order to better interpret these current findings, it would also be interesting to look at the effects of different ethanol doses and conditions on endocannabinoid signalling.

\section{Conclusion}

This combined in vivo small-animal PET and microdialysis study indicates that acute ethanol consumption is associated with enhanced endocannabinoid signalling in the NAcc, indicated by increased CB1R binding and AEA content in that particular brain area. In addition, chronic forced exposure to ethanol indicates further regional dysfunction in CB1R levels, including in the hippocampus and caudateputamen. These changes are reversible within weeks of abstinence. Also, during abstinence, frontal CB1R binding is decreased. The magnitude of these findings in brain areas important for the processing of reward and learning related to addictive behaviour are correlated with the history of ethanol consumption. Taken together, our findings show that acute and chronic ethanol consumption produce relevant in vivo alterations in CB1R levels that deserve further study for the development of rational therapeutic strategies for alcohol dependence and abstinence targeting the ECS.

Acknowledgments The authors thank Ann Van Santvoort, Roma Rietjens and Caroline Vandeputte for their assistance in data acquisition, as well as Merck \& Co, Inc. for providing the $\left[{ }^{18} \mathrm{~F}\right] \mathrm{MK}-9470$ precursor. Brains On-line nv. is acknowledged for their analysis of the microdialysis samples. The financial support of the Research Council of the KU Leuven (OT/10/47) and KUL PF/10/017 (IMIR) is gratefully acknowledged. Cindy Casteels is a postdoctoral fellow of the Flemish Fund for Scientific Research (FWO) and Koen Van Laere is a Senior Clinical Investigator of the FWO.

\section{Conflicts of interest None.}

\section{References}

1. Katona I, Freund TF. Endocannabinoid signaling as a synaptic circuit breaker in neurological disease. Nat Med. 2008;14:923-30.

2. Maldonado R, Valverde O, Berrendero F. Involvement of the endocannabinoid system in drug addiction. Trends Neurosci. 2006;29:225-32.

3. Pava MJ, Woodward JJ. A review of the interactions between alcohol and the endocannabinoid system: implications for alcohol dependence and future directions for research. Alcohol. 2012;46:185-204.

4. Ferrer B, Bermudez-Silva FJ, Bilbao A, Varez-Jaimes L, SanchezVera I, Giuffrida A, et al. Regulation of brain anandamide by acute administration of ethanol. Biochem J. 2007;404:97-104.

5. Rubio M, McHugh D, Fernandez-Ruiz J, Bradshaw H, Walker JM. Short-term exposure to alcohol in rats affects brain levels of anandamide, other $\mathrm{N}$-acylethanolamines and 2-arachidonoylglycerol. Neurosci Lett. 2007;421:270-4.

6. Alvarez-Jaimes L, Stouffer DG, Parsons LH. Chronic ethanol treatment potentiates ethanol-induced increases in interstitial nucleus accumbens endocannabinoid levels in rats. J Neurochem. 2009;111:37-48.

7. Oliva JM, Ortiz S, Perez-Rial S, Manzanares J. Time dependent alterations on tyrosine hydroxylase, opioid and cannabinoid CB1 receptor gene expressions after acute ethanol administration in the rat brain. Eur Neuropsychopharmacol. 2008;18:373-82.

8. Rubio M, de Miguel R, Fernandez-Ruiz J, Gutierrez-Lopez D, Carai MA, Ramos JA. Effects of a short-term exposure to alcohol in rats on FAAH enzyme and CB1 receptor in different brain areas. Drug Alcohol Depend. 2009;99:354-8.

9. Gonzalez S, Cascio MG, Fernandez-Ruiz J, Fezza F, Di Marzo V, Ramos JA. Changes in endocannabinoid contents in the brain of rats chronically exposed to nicotine, ethanol or cocaine. Brain Res. 2002;954:73-81.

10. Vinod KY, Yalamanchili R, Xie S, Cooper TB, Hungund BL. Effect of chronic ethanol exposure and its withdrawal on the endocannabinoid system. Neurochem Int. 2006;49:619-25.

11. Caille S, Alvarez-Jaimes L, Polis I, Stouffer DG, Parsons LH. Specific alterations of extracellular endocannabinoid levels in the nucleus accumbens by ethanol, heroin, and cocaine selfadministration. J Neurosci. 2007;27:3695-702.

12. Gonzalez S, Valenti M, de Miguel R, Fezza F, Fernandez-Ruiz J, Di Marzo V, et al. Changes in endocannabinoid contents in rewardrelated brain regions of alcohol-exposed rats, and their possible relevance to alcohol relapse. Br J Pharmacol. 2004;143:455-64.

13. Ortiz S, Oliva JM, Perez-Rial S, Palomo T, Manzanares J. Chronic ethanol consumption regulates cannabinoid $\mathrm{CB} 1$ receptor gene expression in selected regions of rat brain. Alcohol Alcohol. 2004;39:88-92.

14. Gonzalez S, Fernandez-Ruiz J, Sparpaglione V, Parolaro D, Ramos JA. Chronic exposure to morphine, cocaine or ethanol in rats produced different effects in brain cannabinoid $\mathrm{CB}(1)$ receptor binding and mRNA levels. Drug Alcohol Depend. 2002;66:77-84.

15. Hirvonen J, Zanotti-Fregonara P, Umhau JC, George DT, RallisFrutos D, Lyoo $\mathrm{CH}$, et al. Reduced cannabinoid $\mathrm{CB}(1)$ receptor binding in alcohol dependence measured with positron emission tomography. Mol Psychiatry. 2012. doi:10.1038/mp.2012.100.

16. Ceccarini J, Hompes T, Verhaegen H, Bormans G, Claes S, Van Laere K. Changes in cerebral type 1 cannabinoid receptor (CB1R) availability in ethanol dependent patients after binge drinking and abstinence. J Nucl Med. 2009;50 Suppl 2:1290.

17. Ceccarini J, Gérard N, Bormans G, Claes S, Van Laere K. Ethanolinduced changes in cerebral type 1 cannabinoid receptor availability: an in vivo PET study in healthy human volunteers. J Nucl Med. 2009;50 Suppl 2:310. 
18. Burns HD, Van Laere K, Sanabria-Bohorquez S, Hamill TG, Bormans G, Eng WS, et al. [18F]MK-9470, a positron emission tomography (PET) tracer for in vivo human PET brain imaging of the cannabinoid-1 receptor. Proc Natl Acad Sci U S A. 2007;104:9800-5.

19. Casteels C, Koole M, Celen S, Bormans G, Van Laere K. Preclinical evaluation and quantification of [(18)F]MK-9470 as a radioligand for PET imaging of the type 1 cannabinoid receptor in rat brain. Eur J Nucl Med Mol Imaging. 2012;39:1467-77.

20. Casteels C, Vandeputte C, Rangarajan JR, Dresselaers T, Riess O, Bormans $G$, et al. Metabolic and type 1 cannabinoid receptor imaging of a transgenic rat model in the early phase of Huntington disease. Exp Neurol. 2011;229:440-9.

21. Paxinos G, Watson C. The rat brain in stereotaxic coordinates. San Diego: Academic Press; 1998.

22. Walker JM, Huang SM, Strangman NM, Tsou K, Sanudo-Pena MC. Pain modulation by release of the endogenous cannabinoid anandamide. Proc Natl Acad Sci U S A. 1999;96:12198-203.

23. Giuffrida A, Parsons LH, Kerr TM, Rodriguez De Fonseca F, Navarro M, Piomelli D. Dopamine activation of endogenous cannabinoid signaling in dorsal striatum. Nat Neurosci. 1999;2:358 63

24. Casteels C, Vermaelen P, Nuyts J, Van Der Linden A, Baekelandt $\mathrm{V}$, Mortelmans L, et al. Construction and evaluation of multitracer small-animal PET probabilistic atlases for voxel-based functional mapping of the rat brain. J Nucl Med. 2006;47:1858-66.

25. Luyten L, Casteels C, Vansteenwegen D, Van Kuyck K, Koole M, Van Laere K, et al. Micro-positron emission tomography imaging of rat brain metabolism during expression of contextual conditioning. J Neurosci. 2012;32:254-63.

26. Grueter BA, Brasnjo G, Malenka RC. Postsynaptic TRPV1 triggers cell type-specific long-term depression in the nucleus accumbens. Nat Neurosci. 2010;13:1519-25.

27. Maccarrone M, Rossi S, Bari M, De Chiara V, Fezza F, Musella A, et al. Anandamide inhibits metabolism and physiological actions of 2arachidonoylglycerol in the striatum. Nat Neurosci. 2008;11:152-9.

28. Sugiura T, Kishimoto S, Oka S, Gokoh M. Biochemistry, pharmacology and physiology of 2-arachidonoylglycerol, an endogenous cannabinoid receptor ligand. Prog Lipid Res. 2006;45:405-46.

29. Romero J, Garcia L, Fernandez-Ruiz JJ, Cebeira M, Ramos JA. Changes in rat brain cannabinoid binding sites after acute or chronic exposure to their endogenous agonist, anandamide, or to delta 9-tetrahydrocannabinol. Pharmacol Biochem Behav. 1995;51:731-7.

30. Steffens M, Zentner J, Honegger J, Feuerstein TJ. Binding affinity and agonist activity of putative endogenous cannabinoids at the human neocortical CB1 receptor. Biochem Pharmacol. 2005;69:169-78.

31. Terry G, Liow JS, Chernet E, Zoghbi SS, Phebus L, Felder CC, et al. Positron emission tomography imaging using an inverse agonist radioligand to assess cannabinoid $\mathrm{CB} 1$ receptors in rodents. Neuroimage. 2008;41:690-8.

32. Basavarajappa BS, Cooper TB, Hungund BL. Chronic ethanol administration down-regulates cannabinoid receptors in mouse brain synaptic plasma membrane. Brain Res. 1998;793:212-8.

33. Mitrirattanakul S, Lopez-Valdes HE, Liang J, Matsuka Y, Mackie $\mathrm{K}$, Faull KF, et al. Bidirectional alterations of hippocampal cannabinoid 1 receptors and their endogenous ligands in a rat model of alcohol withdrawal and dependence. Alcohol Clin Exp Res. 2007:31:855-67.

34. Basavarajappa BS, Ninan I, Arancio O. Acute ethanol suppresses glutamatergic neurotransmission through endocannabinoids in hippocampal neurons. J Neurochem. 2008;107:1001-13.

35. Vinod KY, Maccioni P, Garcia-Gutierrez MS, Femenia T, Xie S, Carai MA, et al. Innate difference in the endocannabinoid signaling and its modulation by alcohol consumption in alcoholpreferring sP rats. Addict Biol. 2012;17:62-75.

36. Basavarajappa BS, Hungund BL. Chronic ethanol increases the cannabinoid receptor agonist anandamide and its precursor $\mathrm{N}$ arachidonoylphosphatidylethanolamine in SK-N-SH cells. J Neurochem. 1999;72:522-8.

37. Basavarajappa BS, Saito M, Cooper TB, Hungund BL. Stimulation of cannabinoid receptor agonist 2-arachidonylglycerol by chronic ethanol and its modulation by specific neuromodulators in cerebellar granule neurons. Biochim Biophys Acta. 2000;1535:78-86.

38. Hirvonen J, Goodwin RS, Li CT, Terry GE, Zoghbi SS, Morse C, et al. Reversible and regionally selective downregulation of brain cannabinoid CB1 receptors in chronic daily cannabis smokers. Mol Psychiatry. 2012;17:642-9.

39. Fogaca MV, Aguiar DC, Moreira FA, Guimaraes FS. The endocannabinoid and endovanilloid systems interact in the rat prelimbic medial prefrontal cortex to control anxiety-like behavior. Neuropharmacology. 2012;63:202-10.

40. Tan H, Lauzon NM, Bishop SF, Bechard MA, Laviolette SR. Integrated cannabinoid $\mathrm{CB} 1$ receptor transmission within the amygdala-prefrontal cortical pathway modulates neuronal plasticity and emotional memory encoding. Cereb Cortex. 2010;20:1486-96.

41. Rubio M, Fernandez-Ruiz J, de Migurel R, Maestro B, Michael WJ, Ramos JA. CB1 receptor blockade reduces the anxiogenic-like response and ameliorates the neurochemical imbalances associated with alcohol withdrawal in rats. Neuropharmacology. 2008;54:976-88.

42. Racz I, Bilkei-Gorzo A, Toth ZE, Michel K, Palkovits M, Zimmer A. A critical role for the cannabinoid CB1 receptors in alcohol dependence and stress-stimulated ethanol drinking. J Neurosci. $2003 ; 23: 2453-8$.

43. Henniger MS, Spanagel R, Wigger A, Landgraf R, Holter SM. Alcohol self-administration in two rat lines selectively bred for extremes in anxiety-related behavior. Neuropsychopharmacology. 2002;26:729-36.

44. Goldstein RZ, Volkow ND. Dysfunction of the prefrontal cortex in addiction: neuroimaging findings and clinical implications. Nat Rev Neurosci. 2011;12:652-69.

45. Koob GF, Volkow ND. Neurocircuitry of addiction. Neuropsychopharmacology. 2010;35:217-38.

46. Goldstein RZ, Volkow ND. Drug addiction and its underlying neurobiological basis: neuroimaging evidence for the involvement of the frontal cortex. Am J Psychiatry. 2002;159:1642-52.

47. Everitt BJ, Robbins TW. Neural systems of reinforcement for drug addiction: from actions to habits to compulsion. Nat Neurosci. 2005;8:1481-9.

48. Weissenborn R, Robbins TW, Everitt BJ. Effects of medial prefrontal or anterior cingulate cortex lesions on responding for cocaine under fixed-ratio and second-order schedules of reinforcement in rats. Psychopharmacology (Berl). 1997;134:242-57.

49. Lee DW, Kim SY, Kim JH, Lee T, Yoo C, Nam YK, et al. Quantitative assessment of neurochemical changes in a rat model of long-term alcohol consumption as detected by in vivo and ex vivo proton nuclear magnetic resonance spectroscopy. Neurochem Int. 2013;62:502-9.

50. Vorel SR, Liu X, Hayes RJ, Spector JA, Gardner EL. Relapse to cocaine-seeking after hippocampal theta burst stimulation. Science. 2001;292:1175-8.

51. Schultz W, Tremblay L, Hollerman JR. Reward processing in primate orbitofrontal cortex and basal ganglia. Cereb Cortex. 2000;10:272-84.

52. Hill MN, Patel S, Campolongo P, Tasker JG, Wotjak CT, Bains JS. Functional interactions between stress and the endocannabinoid system: from synaptic signaling to behavioral output. J Neurosci. 2010;30:14980-6. 